Journal of Research in Interprofessional

Practice and

Education

Vol. 1.1

October, 2009

\title{
Effectiveness of a Faculty Development Program in Fostering Interprofessional Education Competencies
}

\author{
Debora Kwan, MSc; Keegan Barker, M.Ed; \\ Denyse Richardson, MD; Susan J. Wagner, MSc; \\ Zubin Austin, PhD
}

\begin{abstract}
Background: To determine the effectiveness of a faculty development program offered to clinical faculty in fostering interprofessional education competencies.

Methods and Findings: A pre-post randomized control group design was used in which only one of two cohorts of clinical faculty received an interprofessional educational intervention. Both cohorts then facilitated case-based interprofessional education sessions for student learners. A variety of outcome measures were used to assess differences between groups in terms of knowledge, skills, and attitudes related to interprofessional education and practice. No significant differences were noted between the control and intervention groups.

Conclusions: The use of a pre-post randomized control group design to measure effectiveness of an educational intervention should be considered to demonstrate the impact of educational interventions.

Keywords: Interprofessional education; Faculty development; Collaborative practice
\end{abstract}

\section{Introduction}

Interprofessional collaboration is emerging as an important paradigm in healthcare $[1,2]$. To support this vision of practice, interprofessional education (IPE) has been identified as an important tool to foster acquisition of knowledge, skills, attitudes, and competencies [3]. Effectiveness of IPE is largely untested despite a large and growing literature that describes and reports (rather than measures) IPE initiatives [4]. Previously, Kwan et al. have proposed a randomized control trial methodology for evaluating effectiveness of faculty development programs on interprofessional education [5].

Within the IPE literature there is general recognition that skilled and knowledgeable faculty are required for successful implementation of IPE, which in turn will promote collaborative practice [6-8]. In particular, Steinert has noted that, in order to support interprofessional collaboration, interprofessional experiential learning is essential [9]. Others have described the need for faculty development, since most clinician-educators may have only limited exposure to or experience with educational theories related to IPE [10-12].

Within the IPE literature related to faculty development there have been studies of a theoretical nature $[13,14]$ and reviews of promising practices [14]. There is little published literature that describes systems for developing, implementing, and evaluating outcomes of faculty development initiatives in IPE. Although anecdotal experiences have been described, there is little empirical evidence supporting the 


\section{JRIPE}

25

Effectiveness of Faculty Development for IPE Competencies

Kwan, Barker, Richardson, Wagner, \& Austin
Journal of Research in Interprofessional Practice and Education

Vol. 1.1

November, 2009
Journal of Research in Interprofessional Practice and Education

effectiveness of faculty development programs. In particular, a literature review failed to produce any published report of the effectiveness of faculty development initiatives using a pre-post randomized control group design, a method that has been identified as useful for establishing the impact of educational interventions [9].

\section{Objective}

The objective of this study was to determine the effectiveness of a faculty development program in fostering interprofessional education competencies in clinical faculty. Our main hypothesis was that clinical faculty who participated in a structured faculty development program in IPE would demonstrate significant improvements in their knowledge, skills, and attitudes related to IPE as compared with those who did not complete this program.

Specific research questions included:

- Are there any differences between the control and intervention groups with respect to knowledge of IPE?

- Does previous experience with IPE or interprofessional care affect knowledge scores?

- Do attitudes toward healthcare teams change as a result of the educational intervention?

- Does time elapsed since the intervention influence attitudes?

- Does previous experience with IPE or collaborative practice affect attitudes?

\section{Methods}

\section{Study Design}

A pre-post randomized control group design was selected for this study. Steinert has described the use of this research design in the context of educational research as an appropriate mechanism for establishing impact of a faculty development program such as this [9]. In this design, one group (the intervention group) is provided with a formalized educational intervention, while another group (the control group) receives nothing. Both groups are randomized using traditional methods to ensure they are comparable. Pre- and post-tests are used to measure acquisition of knowledge and skills and the evolution of attitudes, which may all be associated with the educational intervention, not just attitudes.

\section{Participants}

Participants for this study were clinical faculty from a variety of health disciplines who act as preceptors/supervisors for students in clinical settings. Eligible participants were recruited from three hospital and ambulatory practice sites in Toronto that are involved in clinical practicum for students in medicine, nursing, occupational therapy, pharmacy, physiotherapy, social work, and speech language pathology.

Participants were recruited through e-mail, presentations at meetings and rounds, and direct contact by a research assistant. As part of this first contact process, study objectives and methods were reviewed and discussed. 
Effectiveness of Faculty Development for IPE Competencies

Kwan, Barker, Richardson, Wagner, \& Austin

Journal of Research in Interprofessional Practice and Education

Vol. 1.1

November, 2009
Journal of Research in Interprofessional Practice and Education

Since students' evaluations of the skills of clinical faculty were defined as an important outcome for this study, students from these health profession fields were also separately recruited to participate in this study using e-mail postings, classroom presentations, and direct contact by a research assistant.

All participants (clinical faculty and students) provided written informed consent based on an ethics protocol approved by the University of Toronto and all participating hospital/ambulatory sites.

\section{Description of the educational intervention}

For this study, a customized Faculty Development Program for Interprofessional Education (FDP-IPE) was developed as the educational intervention. This 2.5 day program was based on a previously piloted 40-hour faculty development program developed through a grant from the Royal College of Physicians and Surgeons of Canada (RCPSC).

The FDP-IPE contained three modules designed to expose participants to the knowledge, skills, and attitudes required to foster IPE competencies. Key knowledge outcomes for this program included: a) frameworks for planning IPE, b) understanding of professional roles/responsibilities/scopes of practice [14],c) essential elements of collaborative practice, and d) barriers and facilitators to IPE and Collaborative Practice (CP) [15]. Skills in this program included: a) group process management, b) group facilitation within an interprofessional health context, c) providing feedback, assessment, and evaluation, and d) reflective practice. Attitudes in the program included: a) appreciation of learner-centred educational practices, b) support of IPE and $\mathrm{CP}$ as integral to contemporary healthcare practice, and c) willingness to participate in collaborative education and practice.

Throughout the program, a variety of educational approaches were used, including didactic sessions, role-playing using standardized student-educators (actors portraying students), group discussions, reflection, and reading. Most of the educational material used in this program was adapted from the RCPSC course and customized and condensed for the needs of the participants of this study. A more detailed description of this faculty development program may be found in Appendix 1.

\section{Procedures and randomization}

Clinical faculty volunteered for this study. Although no specific compensation was provided for these participants, non-physicians' workplaces provided them with paid release time from their clinical positions to undertake the training program.

Once enrolled in the study, clinical faculty were randomly assigned to either the intervention (Faculty Development Program) group or the control group. Randomization was undertaken using a random number table. All those randomized to the intervention group received the full 2.5 day FDP-IPE program, whereas none in the control group received any additional formal education in IPE as part of this study. 
Effectiveness of Faculty Development for IPE Competencies

Kwan, Barker, Richardson, Wagner, \& Austin

Journal of Research in Interprofessional Practice and Education

Vol. 1.1 November, 2009
Journal of Research in Interprofessional Practice and Education

Following completion of the FDP-IPE, all participants in both the intervention and the control group were involved in an IPE program with student volunteers. This IPE program consisted of up to four 60-minute, case-based interactive discussions with one clinical faculty participatant acting as the facilitator and a small group of students (2-4) from a variety of professional backgrounds.

Instructions for these sessions were identical for both the intervention and control groups. The objective of each session was for students to learn how health teams function, how each profession contributes to the care of patients, and how healthcare professionals collaborate and communicate to improve patients' health outcomes. Each session was built around case-based discussions specifically developed to be applicable to all professions represented in this study. Cases were developed in areas related to rehabilitation of stroke patients, treatment and monitoring of a patient with diabetes, etc.

Student volunteers were assigned to discussion groups facilitated by clinical faculty who had either completed the FDP-IPE or who had no formal training in principles of IPE. Assignment of students to groups was not randomized since deliberate efforts were made to ensure that, within a specific small group, students were not all from the same profession or of the profession of the facilitator.

\section{Outcomes measurement used}

The second level of the modified Kirkpatrick's Model of Education Outcomes for IPE was identified as the most appropriate method of determining study outcomes using a pre-post randomized control group design [16]. In particular, modification of attitudes/perceptions and acquisition of knowledge and skills were identified as key outcome indicators for clinician educators in the intervention group. To measure these changes, three instruments were selected for use in this study. It is important to emphasize that student discussion groups were used as the vehicle through which assessment of faculty skills in facilitating IPE was measured. That is, faculty members facilitated student discussion groups, thereby having the opportunity to apply knowledge, skills, and attitudes relevant to IPE in a manner that allowed for measurement. Thus, students were asked to evaluate their faculty member's (smallgroup facilitator's) skills as an indirect measure of the effectiveness of the educational intervention.

Changes in clinical faculty's attitudes toward IPE were measured using the Attitudes Toward Healthcare Teams (ATHCT) instrument, a 20-item measure of general attitudes using a 6-point Likert scale [17]. Two subscales are used in the ATHCT: Quality of Care/Process and Physician Centrality (i.e., how central the role of the physician should be within a health team). High scores on the Quality of Care/Process subscale indicate the perception of high quality of care and process within the team, whereas high scores on the Physician Centrality subscale indicate a positive view of physician authority/decision making in teams.

To measure change in clinician-educators' knowledge related to IPE, a 10-item survey was developed by the investigators since no other comparable validated tool had been reported in the literature. This instrument measured knowledge of ele- 
28

Effectiveness of Faculty Development for IPE Competencies

Kwan, Barker, Richardson, Wagner, \& Austin

Journal of Research in Interprofessional Practice and Education

Vol. 1.1

November, 2009 ments of collaborative practice (e.g., roles/responsibilities of different professionals, scopes of practices), understanding of processes in collaborative practice and IPE, etc. A face validation process was undertaken with a group of identified IPE experts to ensure this survey accurately captured the essential knowledge base required for interprofessional education.

Both the ATHCT and the IPE knowledge measurements were administered at two separate points in time: pre-testing was undertaken 3 weeks prior to the FDPIPE (for the intervention group) or immediately before the case-based discussion groups began for the control group, whereas post-testing for both the control and intervention groups occurred within 1 week of the completion of the discussion groups. Tools were administered electronically (using Survey Monkey ${ }^{\mathrm{TM}}$ ) or by paper, depending on participants' preferences.

To measure facilitation skills of clinical faculty, students completed three different instruments after finishing their case-based discussions. The Team Integration Measure (TIM) is a 19-item instrument demonstrating good reliability and validity and measuring the level of integration within the team as perceived by members $[17,18]$. It includes three subscales measuring participation, role clarity, and team functioning and has been used previously in published research [20]. Higher scores indicate a more positive measure of the respective underlying concept. The Team Collaboration Index (TCI) is a 16-item measure of collaboration consisting of three subscales: problem solving through support/integration, open/authentic communication, and knowledge-based risk taking [21]. Higher index scores indicate higher collaborative practices within the team. The TCI has also been used previously and demonstrates good reliability and validity [18]. Finally, the Collaboration Satisfaction About Care Decisions (CSACD) scale was adapted (to make it more applicable for students rather than clinicians, and with the author's permission) and used [22]. This 9item instrument measures collaboration and satisfaction with group processes; higher scores indicate higher perceived collaborative practice and satisfaction with processes.

All three instruments were used to measure students' perceptions of their clinical faculty member's facilitation skills. Psychometric properties of all instruments used in this study were reviewed prior to use [18]. The Team Collaboration Index is noted for its strong theoretical underpinning, ease of administration and scoring, and strong factor loadings on all subscales. This instrument is a reliable measure of collaboration; however, additional testing for validity has not been published, and this has been identified as a possible limitation associated with the use of this tool [19]. The Collaboration Satisfaction About Care Decisions scale is noted for its readability; however, it lacks strong theoretical underpinning, and its use of very strong verbal anchors (such as "always" and "never") has been identified as a potential limitation since many respondents are reluctant to select them. Nonetheless, the scale has been identified as being particularly useful for organizational development purposes, and it demonstrates sufficient reliability for use in this type of research study [18]. The Attitudes Toward healthcare Teams instrument is built upon a solid theoretical foundation consistent with major theories of group development. While its use of very strong verbal anchors has been identified 
29

Effectiveness of Faculty Development for IPE Competencies

Kwan, Barker, Richardson, Wagner, \& Austin
Journal of Research in Interprofessional Practice and Education

Vol. 1.1

November, 2009 as a limitation, it has demonstrated acceptable reliability and validity and is a useful and widely used tool within health services research [18]. The Team Integration Measure has been noted for its strong theoretical foundations, strong reliability and validity, as well as its excellent readability and ease of scoring. Its use of a 7point scale obviates the need for forced-choice answers, and its brevity makes it a useful way of corroborating information from other scales (notably the Attitudes Toward healthcare Teams tool) [18].

All instruments were administered either electronically (using Survey Monkey ${ }^{\mathrm{TM}}$ ) or on paper following completion of the four facilitated group discussions, at which time demographic information for each student was also collected.

\section{Data analysis methods}

For all analyses, SAS statistical software (SAS Inc., 2005) was used. For the analysis of the clinical faculty data, multiple linear models were constructed using general linear models. Models were constructed for our outcomes of interest: change in attitudes (ATHCT), knowledge (IPE knowledge questionnaire), and skills (TCI, TIM, CSACD) using pre-defined predictor variables. These predictor variables were: intervention vs. control group, previous experience with IPE or interprofessional care, and time elapsed since the intervention.

For each outcome, a preliminary model was created that included all predictors. For $p=.10$, non-significant predictors were examined, and the least significant of these was then removed from further analysis. Models were re-run and reduced in this way until a final model emerged which included only predictors associated with $p<.10$. This significance level was chosen because a non-significant result at the $p<$ .05 level would have discouraged further analysis of the data. As such, in this case, we were more concerned with Type II error. Thus, this use of a more liberal alpha was deliberately chosen here to increase the power of the initial analysis. Setting power at $80 \%$ and alpha at .05 is appropriate if damage associated with a Type I error is four times as severe as damage associated with a Type II error. Clearly, this is not the case in this initial analysis. A more stringent $p$-value of .05 was thus set for subsequent analyses, and $p \leq .05$ was used as the cut-off for reporting statistical significance, as suggested by Borenstein, Hedges, Higgins, and Rothstein [23]. ANOVA was used to test for effects of predictor variables on pre- versus post-scores, and $t$-tests were used to compare means.

For the analysis of student data, multiple regression models were constructed using mixed models. This approach was used because scores of students who had participated in the IPE program with the same instructor were not independent of each other. For example, we would expect that all students with a very good clinical faculty would tend to score higher in knowledge related to IPE than a group of students with a poor one since competency of the clinical faculty clearly influences learning outcomes. To control for this clinical faculty effect, this variable was included as a random effect in all mixed models. Other than this difference, student data were then analyzed using the same approach previously described. 


\section{JRIPE}

30

Effectiveness of Faculty Development for IPE Competencies

Kwan, Barker, Richardson, Wagner, \& Austin

\section{Results}

Thirty-seven clinical faculty (males $=9$, females $=28$ ) initially consented to participate in the study. Of these, 12 withdrew prematurely from the study (10 participants withdrew due to time/scheduling/workload conflicts or commitments, and 2 withdrew due to personal/medical reasons). Of the remaining 25 participants who completed participation requirements, 13 were allocated to the intervention group and 12 were allocated to the control group. A demographic profile of clinical faculty is presented in Table 1.

\section{Table 1}

\section{Demographics of study participants}

$\begin{array}{lll}\text { Faculty demographics } & \begin{array}{l}\text { Intervention }(N=13) \\ \text { No. }(\%)\end{array} & \begin{array}{l}\text { Control }(N=12) \\ \text { No. }(\%)\end{array} \\ \text { Gender: Female } & 9(69.2) & 9(75.0) \\ \text { Years teaching: } & & \\ \leq 2 & 3(23.1) & 1(8.3) \\ 3-4 & 1(7.7) & 2(16.7) \\ 5-7 & 1(7.7) & 3(25.0) \\ 8-10 & 1(7.7) & 2(16.7) \\ 11-15 & 3(23.1) & 2(16.7) \\ >16 & 4(30.7) & 2(16.7) \\ \text { Discipline } & & \\ \text { Dietetics } & 1(7.7) & 2(16.7) \\ \text { Medicine } & 1(7.7) & 0(0.0) \\ \text { Nursing } & 1(7.7) & 1(8.3) \\ \text { Occupational therapy } & 3(23.1) & 2(16.7) \\ \text { Pharmacy } & 1(7.7) & 1(8.3) \\ \text { Physiotherapy } & 1(7.7) & 2(16.7) \\ \text { Social work } & 4(30.7) & 3(25.0) \\ \text { Speech language pathology } & 1(7.7) & 1(8.3) \\ \text { Area of practice: } & & \\ \text { Inpatient } & 9(69.2) & 6(50.0) \\ \text { Outpatient } & 3(23.1) & 6(50.0) \\ \text { Not answered } & 1(7.7) & 0(0.0) \\ \text { University status: } & & \\ \text { Lecturer } & 1(7.7) & 2(16.7) \\ \text { Assistant Professor } & 1(7.7) & 0(0.0) \\ \text { Adjunct Professor } & 7(53.8) & 7(58.3) \\ \text { No faculty appointment } & 4(30.8) & 3(25.0) \\ & & \end{array}$

ournal of Research in Interprofessional Practice and Education

In total, 108 health professional students $($ male $=17$, female $=91)$ consented to participate. Thirty-one students (male $=6$, female $=25$ ) subsequently withdrew prematurely from the study due to scheduling or other conflicts. 
Effectiveness of Faculty Development for IPE Competencies

Kwan, Barker, Richardson, Wagner, \& Austin
Journal of Research in Interprofessional Practice and Education

Vol. 1.1

November, 2009
Journal of Research in Interprofessional Practice and Education

The FDP-IPE was conducted at the end of April 2006. The IPE program for students (in both intervention and control groups) was conducted from May to December 2006 (due to rolling group formation and scheduling, based on availability of clinical faculty and students). Complete data were available for 25 instructors and 76 students, and these data were subsequently analyzed.

\section{Demographics of study participants (clinical faculty and students)}

\section{Clinical faculty}

No significant differences $(p>.05)$ between the control and intervention groups were noted based on the demographic variables collected. Area of practice for the clinical faculty participating in this study was slightly skewed to inpatient settings.

A scale was developed to provide a baseline categorization of clinical faculty members' previous involvement in IPE since none could be located in the literature. Clinical faculty were categorized as having either "none-to-moderate" or "high" levels of involvement in IPE (see Table 2). To categorize, clinical faculty were asked to indicate if they had been involved in various types of activities that we had categorized (a priori) as representing these different levels of involvement in IPE. An example of the type of activity categorized in the none-to-moderate level was "a didactic lecture on a clinical topic given to one profession where the lecturer was from a different profession," or "a workshop about a clinical topic where the participants were from various health professions." An example of the type of activity categorized as a high level of involvement in IPE was "workshops where the focus was how to work together and participants were from various health professions" or "clinical practice settings where different health professionals learned about working together and the teachers consisted of a mixed professional group." The main difference between these two categories was whether a) the learning format was didactic or an actual clinical practice setting, b) learners were from one profession or a mix of professions, and c) the learning focus was on a clinical topic area or on learning how to work together more effectively as a team.

The majority of all participants in the study were engaged (as clinicians and/or as clinical faculty) in high-level IPE activities. However, the randomization process utilized ensured that between-group differences were minimized and that the intervention and control groups were demographically comparable.

\section{Students}

Complete data were available for 76 students ( $84 \%$ female). Students were generally distributed in their first (26\%), second (25\%), or third (35\%) year of study in their respective professional program. As discussed previously, in a deliberate effort to ensure that small discussion groups were interprofessional in their make-up, and that clinical faculty facilitating these groups represented a different profession than students in the group, students were not randomized in this study. As a result, and given the professional background of clinical faculty in this study, most students from nursing were placed in the facilitator control group, and most of the second-year students were placed in the facilitator intervention group. Once students were assigned to a 
32

Effectiveness of Faculty Development for IPE Competencies

Kwan, Barker, Richardson, Wagner, \& Austin
Journal of Research in Interprofessional

Practice and

Education

Vol. 1.1

November, 2009
Table 2

\section{Clinical faculty members' previous experience in IPE (Activity Level)}

\begin{tabular}{|c|c|c|c|}
\hline Participant & Facilitator & $\begin{array}{l}\text { Please indicate which activities you have been involved } \\
\text { with as a participant or facilitator. Check all that apply: }\end{array}$ & Activity level \\
\hline & & $\begin{array}{l}\text { - Lectures in my discipline where the lecturer was from another disci- } \\
\text { pline and he/she talked about a clinical topic area } \\
\text { - Lectures in my discipline where the lecturer was from another disci- } \\
\text { pline and the topic was health professional roles and how to work } \\
\text { together } \\
\text { - Lectures that I attended with other learners from one or more other } \\
\text { disciplines where the topic was a clinical/practice area } \\
\text { - Lectures that I attended with other learners from one or more other } \\
\text { disciplines where the topic was health professional roles and how to } \\
\text { work together } \\
\text { - Hands-on activities (e.g., workshops) with other learners from one or } \\
\text { more other disciplines where the topic was a clinical/practice area } \\
\text { - I have not been involved in any such activities }\end{array}$ & $\begin{array}{l}\text { None-to- } \\
\text { moderate }\end{array}$ \\
\hline & & $\begin{array}{l}\text { Hands-on activities (e.g., workshops) with other learners from one or } \\
\text { more other disciplines where the topic was health professional roles } \\
\text { and how to work together } \\
\text { Clinical practice settings where I was taught by teachers from other dis- } \\
\text { ciplines } \\
\text { Clinical practice settings where I was learning/practicing with other } \\
\text { learners from one or more other disciplines and we were taught by } \\
\text { teachers from one discipline } \\
\text { Clinical practice settings where I was learning/practicing with other } \\
\text { learners from one or more other disciplines and we were taught by } \\
\text { two or more disciplines }\end{array}$ & High \\
\hline
\end{tabular}

Note: Clinical faculty answered yes or no to each statement; responses were recorded in column 1. If they answered yes to one or more statements in the none-to-moderate activity level, then they were classified as having none-to moderate experience. If, however, they answered yes to one or more statements in both activity levels, then they were classified as having high experience

group, they stayed with that group for all subsequent case discussions (i.e., same group of students with same facilitator). More than $90 \%$ of all students who volunteered for this study completed at least 3 of the 4 IPE program case discussions.

\section{Outcome measures}

Changes in skills did not differ between faculty in the control and intervention groups. This statement is true for both total scores and sub-scores. 
JRIPE

33

Effectiveness of Faculty Development for IPE Competencies

Kwan, Barker, Richardson, Wagner, \& Austin
Data from all tests used to measure outcomes in this study were examined in order to answer specific questions of interest:

a) Were there any differences between the (faculty) control and intervention groups with respect to knowledge of IPE?

Paired $t$-tests indicated no significant differences between groups, although both groups did show a significant increase in knowledge (Figure 1). While there was no significant change $(p=.11)$ between pre- and post-test scores for knowledge in the control group, a significant difference $(p=.006)$ was noted for the intervention group. This difference suggests that a real improvement in knowledge related to IPE occurred.

b) Does previous experience with IPE or interprofessional care affect knowledge scores?

In this study, both control and intervention groups reported relatively high levels of activity in interprofessional education and interprofessional care. We examined whether

Table 3

\section{Influence of previous experience with interprofessional activities on knowledge scores}

\begin{tabular}{|c|c|c|c|c|}
\hline \multirow[t]{2}{*}{ Activities } & \multirow[t]{2}{*}{ Score type } & \multicolumn{2}{|c|}{$\begin{array}{l}\text { Knowledge score } \\
\text { mean } \pm S D^{a}\left(N^{b}\right)\end{array}$} & \multirow{2}{*}{$\begin{array}{l}\text { P value } \\
\text { for means } \\
\text { comparisor }\end{array}$} \\
\hline & & None to moderate activity level' & High activity level' & \\
\hline \multirow{3}{*}{$\begin{array}{c}\text { Previous } \\
\text { experience in } \\
\text { IPE activites } \\
\text { as a } \\
\text { facilitator }\end{array}$} & $\begin{array}{c}\text { Pre- } \\
\text { knowledge }\end{array}$ & $3.3 \pm 1.0(8)$ & $4.2 \pm 1.1$ (17) & .04 \\
\hline & $\begin{array}{c}\text { Post- } \\
\text { knowledge }\end{array}$ & $5.3 \pm 1.0(6)$ & $4.7 \pm 1.1(18)$ & .25 \\
\hline & $\begin{array}{l}\text { Change in } \\
\text { knowledge }\end{array}$ & $1.7 \pm 1.4(6)$ & $0.7 \pm 1.2(18)$ & .08 \\
\hline \multirow{3}{*}{$\begin{array}{l}\text { Previous } \\
\text { experience in } \\
\text { IPE activites } \\
\text { as a } \\
\text { participant }\end{array}$} & $\begin{array}{c}\text { Pre- } \\
\text { knowledge }\end{array}$ & $3.0 \pm 1.0(5)$ & $4.2 \pm 1.1(20)$ & .04 \\
\hline & $\begin{array}{c}\text { Post- } \\
\text { knowledge }\end{array}$ & $4.6 \pm 1.1(8)$ & $5.0 \pm 1.2(16)$ & .45 \\
\hline & $\begin{array}{l}\text { Change in } \\
\text { knowledge }\end{array}$ & $2.4 \pm 0.9(5)$ & $0.6 \pm 1.1(19)$ & .004 \\
\hline
\end{tabular}

Note: $a=$ Standard deviation; $b=$ Number of participants; $c=$ refer to Table 2 for descriptions 
34

Effectiveness of Faculty Development for IPE Competencies

Kwan, Barker, Richardson, Wagner, \& Austin
Journal of Research in Interprofessional Practice and Education

Vol. 1.1

November, 2009 or not this high base-line activity might affect (likely negate) the impact of the educational intervention. ANOVA models were used to test for the effects of both activity group and control versus intervention group on pre- and post-knowledge scores. Results are presented in Table 3. In both cases, there was no statistical significance for activity in the intervention group; differences in post-knowledge scores between the two activity groups were not significant $(p=.25)$. As expected, pre-knowledge scores were significantly higher among faculty with high levels of activity in both control and intervention groups than among faculty with none-to-moderate activity levels $(p=.04)$.
Figure 2

Box plots for change in attitude scores for control and intervention groups
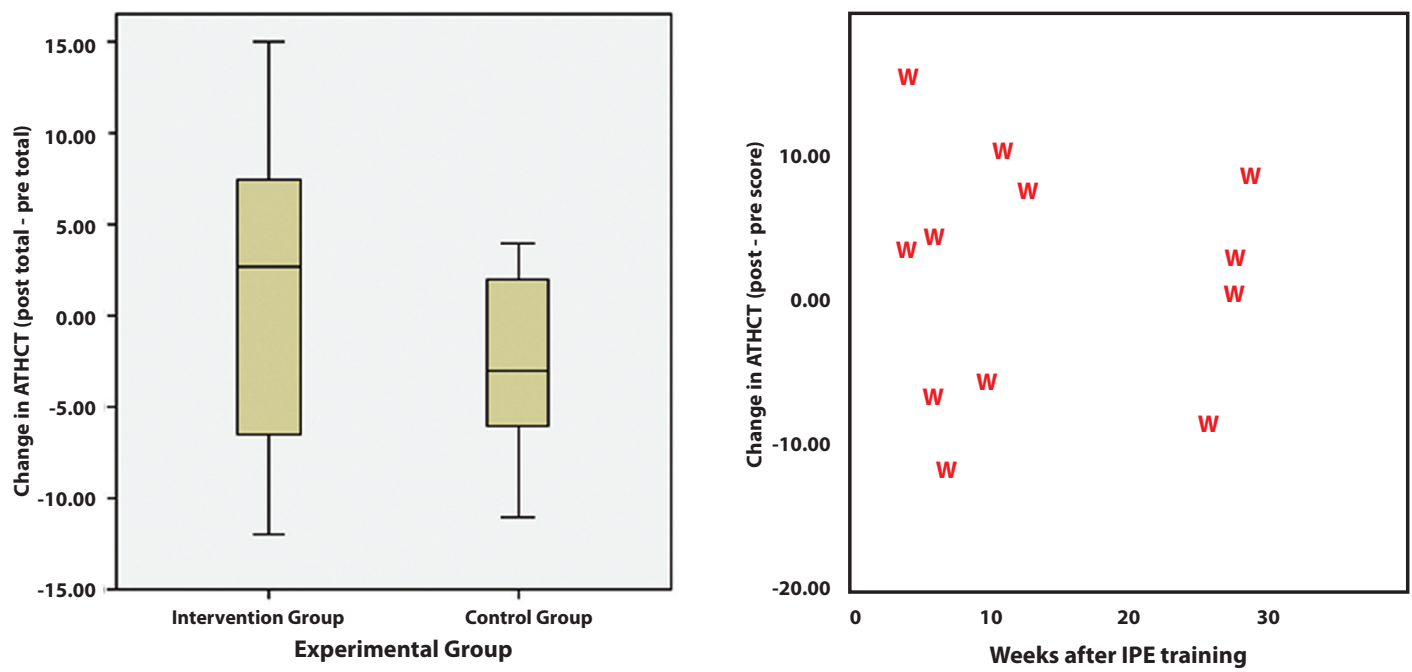

c) Did attitudes toward healthcare teams change as a result of this intervention?

Paired $t$-tests (see Figure 2) demonstrated no significant differences in either the overall attitude score or individual attitude subscales of the ATHCT as a result of this intervention. The control faculty actually showed a slight reduction in the total attitude post-score, whereas the intervention faculty showed a slight increase; $t$-tests failed to show that these changes were statistically significant (intervention: $p=.6$; control: $p=.07)$.

d) Does time elapsed since the intervention influence attitudes?

We examined the question of whether or not elapsed time (and consequently, exposure to IPE and interprofessional care) might influence attitudes toward health teams. We believed this was an important variable to explore because although the control group received no formal educational intervention, they were still exposed to IPE and interprofessional care during this study simply by being facilitators in the small group tutorials. Based on the findings of a regression analysis, time elapsed was not a significant predictor of ATHCT post-scores $(p=.58)$, nor was it a significant predictor of the change in ATHCT scores $(p=.89)$ see Figure 3$)$. 
35

Effectiveness of Faculty Development for IPE Competencies

Kwan, Barker, Richardson, Wagner, \& Austin
Journal of Research in Interprofessional Practice and Education

Vol. 1.1

November, 2009
Table 4

Influence of previous experience with interprofessional activities on attitude scores

\begin{tabular}{|c|c|c|c|c|}
\hline Activities & Time period & \multicolumn{2}{|c|}{$\begin{array}{c}\text { Total attitude score } \\
\text { mean } \pm \text { SDa }^{\mathbf{a}}\left(\mathbf{N}^{\mathbf{b}}\right)\end{array}$} & $\begin{array}{c}\text { P value } \\
\text { for means } \\
\text { comparison }\end{array}$ \\
\hline $\begin{array}{c}\text { Previous } \\
\text { experience in } \\
\text { IPE activites } \\
\text { as a } \\
\text { facilitator }\end{array}$ & Pre & $69.8 \pm 8.3(8)$ & $71.2 \pm 9.3(16)$ & .34 \\
\cline { 2 - 5 } & Post & $65.0 \pm 6.5(6)$ & $72.7 \pm 7.2(18)$ & .02 \\
\hline $\begin{array}{c}\text { Previous } \\
\text { experience in } \\
\text { IPE activites } \\
\text { as a } \\
\text { participant }\end{array}$ & Pre & $71.0 \pm 9.5(5)$ & $70.7 \pm 9.0(20)$ & .88 \\
\cline { 2 - 5 } & Post & $71.0 \pm 1.0(5)$ & $70.7 \pm 7.6(19)$ & .74 \\
\hline
\end{tabular}

Note: $\mathrm{d}=$ Standard deviation; $\mathrm{b}=$ Number of participants; $c=$ refer to Table 2 for descriptions

e) Does previous experience with IPE or collaborative practice affect attitude?

We examined the relationship between base-line activity levels in IPE and interprofessional care, and attitude scores in the pre- and post-periods. Four ANOVA models were used to test the effects of both activity group (none-to-moderate and high) and intervention group on pre- and post-attitude scores (see Table 4 and Figure 4). The intervention was not a significant predictor $(p>.05)$ of outcome. This predictor was removed from the model before testing for activity level. Previous experience with IPE did not affect attitude scores.

\section{Discussion}

The lack of available studies measuring impact of faculty development initiatives in the area of IPE prompted us to undertake this study. We had hypothesized that the educational intervention would improve knowledge, skills, and attitudes of participants as compared with the control group. Results of this study are inconclusive at best and demonstrate only sporadic and inconsistent improvements in these scores.

At first glance, these data suggest that the educational intervention was not successful in producing meaningful improvements in faculty knowledge and attitudes. There are several possible explanations for this observation. First, the faculty development initiative used for the intervention may not have been appropriate or effective for this cohort. It is important to recall that this study took place within the context of an academic health centre, within which interprofessional care is routinely promoted and practiced. Consequently, most of the faculty involved had a relatively high base-line level of knowledge related to interprofessionalism and (arguably) would have "bought in" and had a relatively high base-line attitude 


\section{JRIPE}

36

Effectiveness of Faculty Development for IPE Competencies

Kwan, Barker, Richardson, Wagner, \& Austin
Journal of Research in Interprofessional Practice and Education

Vol. 1.1

November, 2009
Figure 4

Attitudes toward healthcare teams as a function of activity level (i.e., none-to-moderate or high) for intervention and control groups

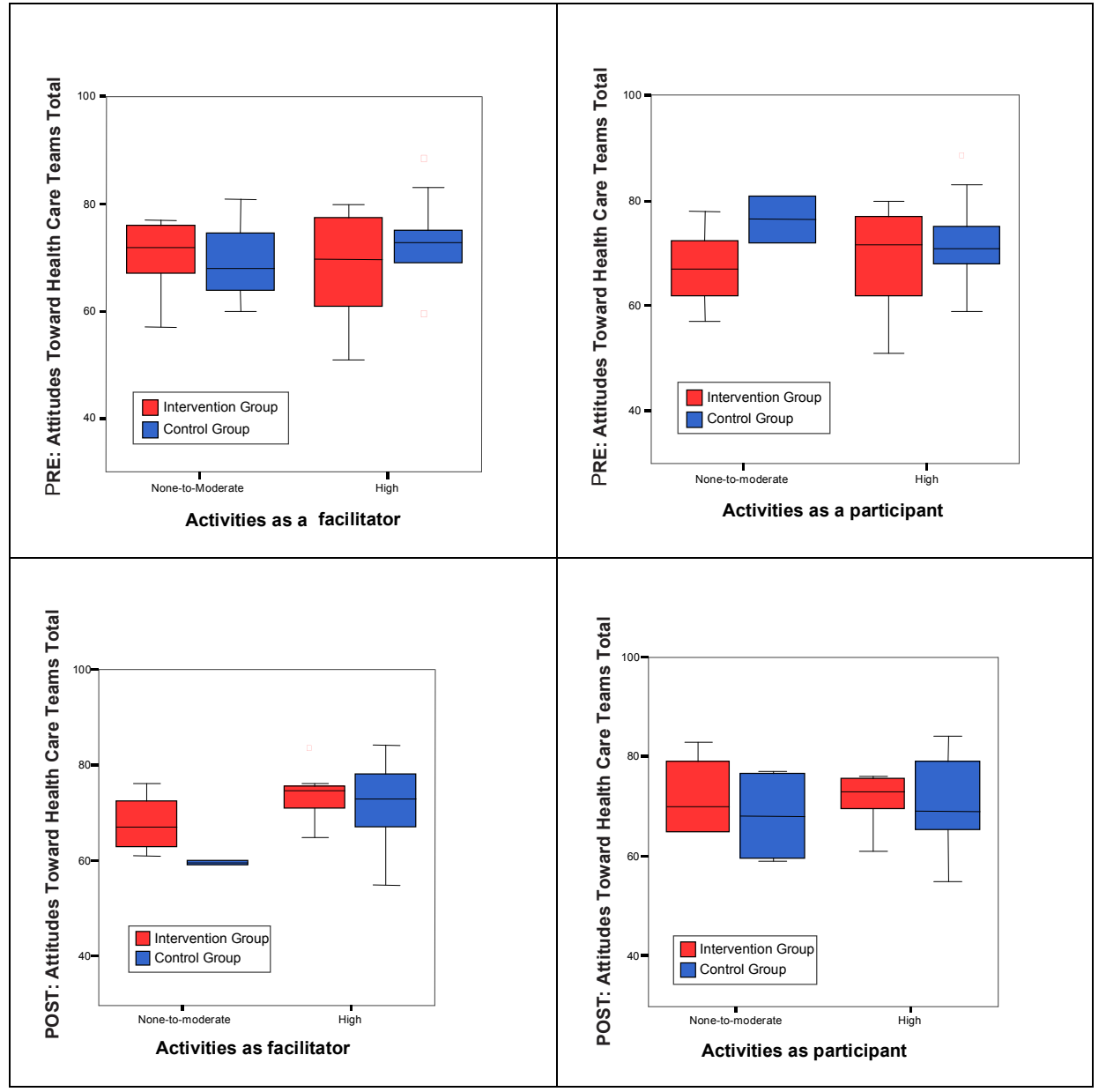

toward interprofessionalism simply by virtue of working within such an environment. The data could be interpreted to suggest a "ceiling effect" for both the control and intervention groups in which faculty development did not necessarily prompt any meaningful growth in knowledge and attitudes in the intervention group. As such, this particular faculty development initiative in this group of participants may be seen as "preaching to the choir."

Alternatively, the lack of significant results in this study could be indicative of methodological problems associated with the measurement of outcomes. Although the tools used in this study were all previously validated, the identification of knowledge and attitudes as key outcomes may have been problematic. We had initially selected these outcomes because validated tools for their measurement existed and because educational researchers have previously demonstrated how they may be used to assess success of an educational intervention using a pre-post design methodology. Arguably, had we identified and measured other outcomes, such as self-reported/perceived gain in knowledge/skills related to IPE, or simple participant satisfaction, more meaningful results may have emerged. Nonetheless, using 
37

Effectiveness of Faculty Development for IPE Competencies

Kwan, Barker, Richardson, Wagner, \& Austin

Journal of Research in Interprofessional Practice and Education

Vol. 1.1

November, 2009 this well-accepted methodology, the lack of significant results must be accepted.

Our findings, coupled with a lack of literature providing any evidence of the effectiveness of faculty development in promoting interprofessional education competencies, suggest a third alternative to consider: faculty development may indeed be a necessary but insufficient intervention in fostering interprofessional education competencies. There are some encouraging data that suggest some differences (though not necessarily significant) emerged in the intervention group; further reinforcement, or alternative methods for reinforcing these positive trends, may have produced more definitive results. For example, within this study, there was no real incentive for participants to actually learn or perform in any particular way since all participants were volunteers, and there was little or no personal investment involved. Unfortunately, in most real-world clinical settings where IPE is taught and modeled, there are few extrinsic motivators to induce behavioural change. The extent to which education such as faculty development must be matched with extrinsic motivators to actually produce meaningful, significant behavioural and attitudinal change needs to be explored further. We believe this point is crucial in interpreting the results of this study: the extent to which an individual internalizes and adopts any education intervention will be, in part, a function of the environment within which s/he is rewarded for doing so. Education for education's sake, while marginally meaningful for an individual, may not translate into expected changes in an environment that does not align rewards and behaviours appropriately. It is important to note that we did not undertake any intervention at the institutional/organizational level, only at the individual/instructor level.

Despite a lack of meaningful outcomes in this study, we believe further work in this area is warranted. In presenting our work, we do not wish to imply that faculty development is meaningless. Instead, we believe that our expected outcomes may not have been achieved for a variety of reasons. First, the previously mentioned lack of congruence between the faculty development initiative and extrinsic environmental motivators may have resulted in less meaningful learner uptake. Second, the true value of any educational intervention may not be immediately apparent; a longer time-frame for this study, tracking individuals over years of practice rather than the weeks immediately following the intervention, may have produced positive results (although linking these results with the intervention itself would become, consequently, that much more difficult). This perhaps indicates the need for ongoing or "booster" sessions to promote reinforcement of knowledge and skills related to IPE. Finally, and perhaps most importantly, we may not have accurately defined and captured the true essence of what "success" in interprofessional education actually means. In opting for very traditional knowledge and attitude outcomes, we may not have actually measured a very important outcome of interest-the affirmation of pre-existing knowledge and practice [24,25].

Importantly, this study represents one of the first published attempts to use a prepost randomized control group within the context of a faculty development initiative in IPE. In identifying measurement tools and describing a methodology, we hope we have provided an example of how such research can be undertaken. We 
Effectiveness of Faculty Development for IPE Competencies

Kwan, Barker, Richardson, Wagner, \& Austin

Journal of Research in Interprofessional Practice and Education

Vol. 1.1

November, 2009
Journal of Research in Interprofessional Practice and Education

interpret our findings through the lens of methodological limitation and identify this as an important area for subsequent research: the development of methodologies, tools, and outcome indicators in the context of IPE will be crucial if its value is to be empirically demonstrated.

\section{Limitations}

The methodology selected for this study was not intended to demonstrate a conclusive or causal link between the educational intervention and changes in outcome measures; instead it was selected in an attempt to demonstrate an association between the two. Since our results were inconclusive, no such association is claimed.

For logistical reasons, we were unable to control for faculty variation with respect to previous experience in IPE or collaborative practice, and this may have influenced our results. Given the widespread acceptance of IPE and collaborative care principles within the institutions involved in this study, it may be argued that the FDP-IPE was simply preaching to the converted, and consequently, the lack of meaningful results was actually an artifact of an already high-functioning, collaborative group of participants.

For similar logistical reasons, students who participated in this study were at different levels of their education, professional development, and clinical experience. Though randomization was attempted, the need to ensure representation from different professions within each small group made true randomization impossible. This may have consequently affected group composition, which in turn may have affected overall results.

As discussed previously, we developed, undertook face validation of, and utilized a bespoke instrument to measure change in clinician-educators' knowledge related to IPE. This 10-item survey was developed by the investigators, since no other comparable validated tool had been reported in the literature. This instrument measured knowledge of elements of collaborative practice (e.g., roles/responsibilities of different professionals, scopes of practices), understanding of processes in collaborative practice and IPE, etc. Given the constraints of this project, we were unable to undertake a more elaborate and complete examination of the psychometric properties of this instrument. As a result, this instrument may not be sufficiently valid or reliable for research purposes. We have attempted to mitigate this reality by using other more psychometrically robust instruments throughout the study and by not relying solely on results from this particular tool for any major conclusions related to this research.

In research such as this, it is difficult to control for external factors such as additional continuing education or local incentives provided by employers to practice collaboratively. These external factors may, of course, have influenced our results in ways that we have not been able to track.

Although the randomized methodology used in this study does not necessarily establish a causal link between the educational intervention and changes in these measures, it can be useful in demonstrating an association between an educational program and outcomes of interest. 
39

Effectiveness of Faculty Development for IPE Competencies

Kwan, Barker, Richardson, Wagner, \& Austin
Journal of Research in Interprofessional Practice and Education

Vol. 1.1

November, 2009

\section{Conclusion}

Despite the numerous "show-and-tell" examples of faculty development to support IPE in the literature, there has been little work published to demonstrate empirically the value of such an intervention. This study outlined a methodological approach to demonstrating significance; results, however, were inconclusive. Further work to develop appropriate methodologies is required to truly assess the value of faculty development initiatives.

\section{Acknowledgements}

We would like to acknowledge Chau Du, Research Analyst and our co-investigators: Ivy Oanadasan, Carole Chatalalsingh, Valerie Grdisa, Sylvia Langlois, James Meuser, Azadeh Moaveni, Roxanne Power, Sandy Rennie and Lynne Sinclair.

\section{Competing interests}

The authors have no competing interests.

\section{References}

1. Gardner, S.F., Chamberlin, G.D., Heestand, D.E., Stowe, C.D. (2002). Interdisciplinary didactic instruction at academic health centers in the United States: Attitudes and barriers. Advance Health Science Education, 2(2), 179-190.

2. Institute of Medicine. (2001). Crossing the quality chasm: A new health system for the $21^{\text {st }}$ century. Washington: National Academy Press.

3. Gill, J., \& Ling, J. (1995). Interprofessional shared learning: A curriculum for collaboration. In Soothill, K. Mackay, L. \& Webb, C. (Eds.), Interprofessional relations in healthcare, (pp. 97-108). London: Edward Arnold.

4. Zwarenstein, M., Reeves, S., \& Perrier, L. (2005). Effectiveness of pre-licensure interprofessional education and post-licensure collaborative interventions. Journal of Interprofessional Care, 19(S1), 148-165.

5. Kwan, D., Barker, K.K., Austin, Z., Chatalsingh, C., Grdisa, V., Langlois, S., et. al. (2006). Effectiveness of a faculty development program on interprofessional education: A randomized control trial. Journal of Interprofessional Care, 20(3), 314-316.

6. Mathias, P., \& Thompson, T. (1997). Preparation for interprofessional work: Trends in education, training, and the structure of qualifications in the United Kingdom. In Ovretveit, J., Mathias, P., \& Thompson, T. (Eds.), Interprofessional working for health and social care. (pp. 47-55). Basingstoke: MacMillan.

7. Parsell, G., Bligh, J. (1998). Interprofessional learning. Postgrad Med Journal, 74, 89-95.

8. Waugaman, M. (1994). Socialization and interprofessional practice. In Casto, M. (Ed.), Interprofessional care and collaborative practice, (pp. 27-47). New York: Brooks Coles.

9. Steinert, Y., Mann, K., Centeno, A., Dolmans, D., Spencer, J., Gelula, M. \& Prideaux, D. (2006). A systematic review of faculty development initiatives designed to improve teaching effectiveness in medical education: Best Evidence Medical Education Guide No. 8. Medical Teacher, 28(8), 497-526.

10. Barr, H. (1994). NVQs and their implications for interprofessional education. In Leathard. A, (Ed.). Going interprofessional: working together in health and welfare. London: Rougledge.

11. Casto, M. (1994). Education for interprofessional practice. In Casto, M. (Ed.), Interprofessional care and collaborative practice. New York: Brooks Coles.

12. Graham, J., \& Wealthall, S. (1999). Interdisciplinary education for the health professions: Taking the risk for community gain. Focus on Health Professional Education, 1(1), 49-69.

13. D’Amour, D., \& Oandasan, I. (2005). Interprofessionality as the field of interprofessional practice and interprofessional education: An emerging concept. Journal of Interprofessional Care, 19(S1), 8-20.

14. Oandasan, I., \& Reeves, S. (2005). Key elements for interprofessional education, Part I: The learner, the educator, and the learning context. Journal of Interprofessional Care, 19(S1), 21-38. 


\section{JRIPE}

40

Effectiveness of Faculty Development for IPE Competencies

Kwan, Barker, Richardson, Wagner, \& Austin

\section{Journal of Research in Interprofessional Practice and Education}

15. Way, D.O., Busin, N., \& Jones, L. (2000). Implementation strategies: "Collaboration in primary care - family doctors and nurse practitioners delivering shared care." Toronto, ON: The Ontario College of Family Physicians.

16. Freeth, D., Hammick, M., Koppel, I, Reeves, S., \& Barr, H. (2002). A critical review of [evaluations of] interprofessional education. Occasional Paper \#2. The Higher Education Academy, Health Sciences and Practice, 1-63.

17. Heinemann, G.D., Schmitt, M.H., Farrell, M.P., Brallier, S.A. (1999). Development of an Attitudes Toward healthcare Teams Scale. Evaluation \& the Health Professions, 22(1), 123-42.

18. Heinemann, G.D., \& Zeiss, A.M. (2002). Team performance in healthcare: Assessment and development. New York: Kluwer Academic/Plenum Publishers.

19. Lichtenstein, R., Alexander, J.A., Jinnett, K., \& Ullman, E. (1997). Embedded intergroup relations in interdisciplinary teams: Effects on perceptions of level of team integration. The Journal of Applied Behavioural, 33(4), 413-435.

20. Aram, J.D., Morgan, C.P., \& Esbeck, E.S. (1971). Relation of collaborative interpersonal relationships to individual satisfaction and organizational performance. Administrative Science Quarterly, 16(4), 289-296.

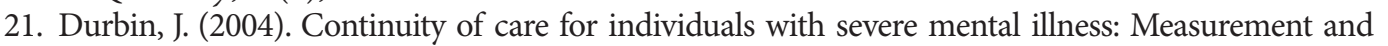

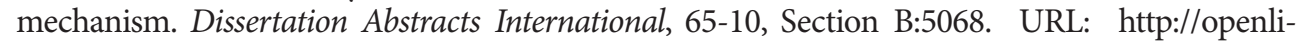
brary.org/b/OL19887318M/Continuity_of_care_for individuals_with severe mental_illness: [September 18, 2009).

22. Baggs, J.G. (1994). Development of an instrument to measure collaboration and satisfaction about care decisions. Journal of Advanced Nursing, 20(3), 176-82.

23. Borenstein, M., Hedges, L.V., Higgins, J.P.T., \& Rothstein, H.R. (2009). Introduction to meta analysis. Chichester West Sussex (GB): John Wiley \& Sons.

24. Crowley, S.D., Owens, T.A., Schardt, C.M., Wardell, S.I., Peterson, J., et al. (2003). A web-based compendium of clinical questions and medical evidence to educate internal medicine residents. Academic Medical Journal, 78(3), 270-274.

25. Sackett, D.L., Strauss, S.E. (1998). Finding and applying evidence during clinical rounds: The "evidence cart." Journal of the American Medical Association 280(15), 1336-1338.
Journal of Research in Interprofessional Practice and Education

Vol. 1.1

November, 2009 
41

Effectiveness of Faculty Development for IPE Competencies

Kwan, Barker, Richardson, Wagner, \& Austin
Journal of Research in Interprofessional Practice and Education

Vol. 1.1 November, 2009

\section{Appendix 1 \\ Faculty Development Program for Interprofessional Education (FDP-IPE)}

Adapted with permission from: Teaching Health Professionals to be Collaborators for Patient Centred Care: A Faculty Development Proposal to Develop Leaders in Interprofessional Education. Oandasan I, Silver I, Sinclair L, Leszcz M, Robb A, Richardson D, Kwan D, Moaveni A, Barker K. Royal College of Physicians and Surgeons/Associated Medical Services CanMEDS Research and Development Grant (2004-05).

Course goal and objectives for each module

- Goal of Program: To advance participants' understanding and ability to teach others about interprofessional collaboration.

- Program length: 2.5 days, 3 modules

- Format: The program incorporated the principles of andragogy and utilized didactic/experiential learning, DVD vignettes, case discussion, and standardized learners. One or two readings were pre-circulated prior to each module.

Module 1 - Professional and collaborator roles (1/2 day)

Objectives:

- Explain how interprofessional education is related to collaborative practice.

- Explain the importance of: professional role understanding, role blurring and its negotiation, and stereotypes as essential components for collaborative practice.

- Describe the relationship between the clarity of one's health professional role and the collaborator role health professionals should develop.

Module 2 - Collaborative teams ( 1 day)

Objectives:

- Describe the theoretical and conceptual framework for collaborative practice.

- Identify challenges and benefits of working in an interprofessional team.

- Develop and integrate an understanding of the importance of reflection on and attentiveness to the group process that is integral to effective team practice.

Module 3 - The IPE facilitator (1 day)

Objectives:

- Practically build upon a theoretical foundation of interprofessional facilitation by developing knowledge, skills, and attitudes in:

- Group dynamics-stages of development

- Giving and receiving feedback

- Approaches to conflict resolution (acknowledge and deconstruct conflict in a team).

For further information, please contact Debora Kwan (Debbie.kwan@uhn.on.ca) or Keegan Barker (keegan.barker@uottawa.ca). 